\title{
Planning Techniques Needed to Improve the Teaching and Learning of Basic Technology in the Junior Secondary Schools in Nigeria
}

\author{
Nicholas Ogbonna Onele* \\ Department of Vocational Teacher Education, University of Nigeria, Nsukka, Nigeria \\ *Corresponding author: nicelinks@yahoo.com
}

Received October 23, 2013; Revised January 09, 2014; Accepted January 14, 2014

\begin{abstract}
This study on the workshop planning techniques needed to improve the teaching and learning of basic technology in Nigeria adopted a survey research design. A sample of 861 respondents was selected for the study. A structured questionnaire consisting of 25 items was developed and used for data collection. The Pearson- Product Moment Correlation Coefficient was used to determine the internal consistency of the instrument. The data collected were analyzed using Mean statistic in order to answer the research question posed for this study, while Analysis of Variance was used to test the null hypothesis at a 0.05 degree of significance. Based on the data analyzed, it was found from the study that twenty four workshop planning techniques are needed. There was no significant difference in the mean responses of the school administrators, basic technology teachers and the basic technology workshop staff on the planning techniques needed for the teaching and learning of basic technology in Nigeria.
\end{abstract}

Keywords: planning, technique, basic technology, teaching and learning

Cite This Article: Nicholas Ogbonna Onele, "Planning Techniques Needed to Improve the Teaching and Learning of Basic Technology in the Junior Secondary Schools in Nigeria." American Journal of Educational Research 2, no. 1 (2014): 23-28. doi: 10.12691/education-2-1-5.

\section{Background of the Study}

The workshop for the teaching and learning of basic technology needs to be well planned. According to Ezeji [6], a workshop is a unique learning situation in which learners may experiment, test, construct, assemble, disassemble, repair, design, create, imagine and study. Workshop is generally a place where practical activities involving measurement, cutting, sizing, smoothing, assembly, repairs, finishing among other activities, are carried out. The workshop, therefore, provides a space where students of basic technology practicalize what they were taught in the classroom, as well as for storing the equipment, tools and materials used for such practical purposes. Effective teaching and learning of basic technology, demands a workshop in which the theory learnt in the classroom can be translated into a practical demonstration by both staff and students. This is because basic technology cannot be taught successfully without equipment and tools which are appropriately kept in the laboratory [7].

Basic technology is a course of study introduced in the year 2007 into the Primary and Junior Secondary School levels of the 9-3-4 system of education presently practiced in Nigeria. It is an amalgamation of many subjects. These subjects include; electrical/electronics, metal work, simple mechanics, wood work, technical drawing, food processing, rubber and plastic technology [9]. However, the purposes of pre-vocational training given to students at the Primary and Junior Secondary School levels are: introduction into the world of technology towards interest arousal and choice of a vocation at the end of Junior Secondary School and professionalism later in life; exposing students to career awareness by exploring usable options in the world of work; and enabling youths to have an intelligent understanding of the increasing complexity of technology, (Federal Republic of Nigeria, 2007 ). As Comparative Education Study and Adaptation Center [3] puts it, the objectives include:

(i) To provide pre-vocational orientation for further training in technology.

(ii) To provide basic technology literacy for everyday living and

(iii) To stimulate creativity (p. vii).

In order to achieve these objectives, the syllabus and the course books are structured and written in ways that would require the use of tools and equipment in appropriate environment. Such appropriate environment may be found especially in the laboratory or workshop.

Basic technology is an indispensable pre-vocational base on which future vocational choices are made. In their separate works, Ezeji, [6], Nwachukwu, [18], Ogwo and Oranu, [20] and Okoro [21] all established that prevocational training requires same facilities and similar curriculum components as will be required in the real vocation, though at introductory levels. These components include; general education, theory and related courses, workshop practice, industrial training/production work, 
and small business management and entrepreneurial training.

Planning is an inevitable aspect of an effective workshop management strategy. Planning, as in all management processes, is the first logical step in facility management. Workshop planning technique is a method or approach by vocational education personnel, schools and industries in the day-to-day provision and utilization of workshop facilities for optimum achievement of set goals. Planning is the "process of preparing a set of decisions for action in the future, directed at achieving goals by optimal means" $[1,4]$. Planning is a proactive process and entails decisions on how things will be done before hand. In the basic technology workshop, things to plan include the shape and size of the shop, number of personnel, space needs, timing, to mention but a few [6]. Planning involves selecting missions and objectives as well as actions to take in order to achieve them.

It therefore, implies that before anything good comes out of any endeavour, it has to be planned. Planning in education is a well articulated conceptualization of the educational philosophy, goals, objectives and specification for short and long term objectives including implementation of the planned curricula. It also includes budget priorities for facilities management [10]. On the other hand, Ezeji, [6] asserted that vocational laboratories are designed to reflect the curriculum and the desired level of education. The author stressed that 'true planning must identify the programme philosophy, specific objectives, teacher and pupil activities, enrollments to be served, financial resources, course content, and laboratory equipment before these are converted into graphic forms' (P.1). The essence of applying workshop planning technique is for the institution to meet up with its educational objectives, [15].

The quality and quantity of practical experience gained by junior secondary school pupils in basic technology is predicated on the availability of facilities and the management of such facilities. Okoro [21] pointed out that a good quality programme is housed in physical facilities which are adequate, well - planned and properly directed to provide realistic education. UNESCO [27] had stressed that for quality assurance in technological development to be achieved; responsible national authorities should establish criteria and standards, subject to periodic review and evaluation, to be applied to all aspects of technical and vocational education. Such criteria and standards should include physical facilities, buildings, libraries, workshop layout, quality and type of equipment, as well as safety measures meant to create a conducive learning environment. Such a recommendation requires planning of workshop facilities to enhance instructional activities and subsequent achievement of the objectives of setting up the programme.

Ogwo [19] lamented that none of the technology workshops in Nigeria approaches the ideal in shop layout and most of the present shop arrangements are the result of a series of compromises. This means that the errors seen in shop planning can be eliminated by a careful consideration of many factors. This consideration is referred to as "planning analysis" [12]. Furthermore, Okoro [21] noted that in a school system, the principal may be directly involved in planning new programmes or in planning the expansion of existing progrmmes and may be required to submit specifications for new workshops, classroom blocks and equipment and to make proposals for course offerings. The author suggests that for submitting any proposal for building, equipment and materials, the principal has to bear in mind the following 17 questions:

1. What is the nature of the course of study to be introduced or expanded?

2. At what level will the course be offered?

3. Will courses be offered as part of JSS, SSS, technical college or polytechnic?

4. How many classrooms and workshops are needed for each course of study or subject area?

5. How many students are expected to make use of each classroom or workshop at a time?

6. Will there be a separate workshop for each subject or will there be a multipurpose workshop?

7. Will there be separate lecture rooms and workshops or will workshops serve for both lectures and practical works?

8. What are the sizes of workshops and classrooms required?

9. For how many hours a day will each workshop be in use?

10. What are the number and sizes of offices and storage rooms required?

11. What are the number and sizes of wash rooms and toilets required?

12. How will the building be wired to provide adequate lighting and suitable outlets for the connection of machines and other equipment?

13. How will switches be located for convenience and safety?

14. What are the different machines, tools and equipment required for each course or programme?

15. What is the number required of each machine, tool and equipment?

16. Where exactly on the workshop floor will each machine, tool, equipment and work bench be located?

17. How close to classrooms and offices should workshops be?

Grimaldi and Simonds [13] stressed that adequate working spaces has to be provided around electrical power supply equipment for the comfortable performance of normal operating and maintenance tasks in the workshop. The authors further stated that secured footing should also be certain when equipment is exposed while in service. Similarly, Ezeji [6] noted that for the design of effective layout of workshops, it is important that equipment items be described as to size and the floor area needed for its operation. Without adequate descriptions, architects are not able to provide a reasonable and safe operating space around the equipment. Such inadequacy is able to hinder effective and safe utilization of the equipment.

On lighting and visual control, Ezeji [6] emphasized that natural and artificial lighting should be supplementary to each other. The positioning of the workshop should be done to provide abundant natural light or reflected glare should be avoided as much as possible. This is because glare constitutes a threat to the safe working condition of the worker in the workshop [2,19]. Ogwo [19], however added that a glass area equal to one - fifth the floor areas should be provided in each workshop room, while the 
height of the windows should be equal to one - half the width of the floor space. Furthermore, the lower level of the windows should be above the benches which may be placed in front of the windows. In the opinion of Ezeji [6], it is vital to shade windows on the sides of the building that are exposed to the sun and/or be of heat absorbing glass to increase its temperature control requirements. The author reiterated that florescent lighting is preferred to incandescent lighting but cautioned that stroboscopic effects on moving machinery should be avoided. Grimaldi and Simonds [13] had earlier stressed that illumination has to be adequate in work areas and must be, up to $50 \mathrm{ft}$ candelas. These authors maintained that auxiliary power supply system should be provided in the work areas, in order to ensure a continuous illumination. Such provisions could be stand - by generators, or solar energy converter and will serve as vital source of energy in the case of emergency power outage. In his emphasis on the importance of lighting in the school workshops, Ogwo [19] confirmed that the provision of adequate quality light leads to less eye strain, greater accuracy of work, more rapid progress, better use of floor space, greater shop cleanliness, improved class interest and participation and a drastic reduction in the number of workshop accidents on the side of both the staff and pupils.

Ogwo [19]; Mohammed [15]; Asiabaka [1], in deferent studies, called for adequate provision of wash fountains as well as proper cleaning compounds within the workshop to alleviate some undesirable conditions that could come after workshop practices. Such conditions include dust, odor, grease, gum and even itching of the body on the side of the users of the shop. According to Mohammed [15], it is a common knowledge that workshop facilities utilization has been witnessing perpetual increases in the number of its users as a result of higher demands for education by the ever growing population of the citizenry without a commensurate increase in the number of facilities. The author buttressed that lack of projection for the unabated increases in the students enrolment in the course of workshop facilities planning has rendered many industrial technical education workshops in the schools inadequate for students currently enrolled into those schools. In separate studies, Esomonu [5]; Oranu, [22]; Steiss [23]; and Tahir [24], agreed that the astronomical increase in students' enrolment is challenging the effective realization of the goals of vocational and technical education especially in Nigeria. This is because laboratories and workshops that were built to serve a small school population are presently put to use by greater than double the initial planned population. Oranu [22] contended that the same logic for space consideration is applicable to the number and sizes of equipment, tools and materials. It is therefore, expedient and in fact necessary that educational enrolments, which in recent times, have exploded massively should be analyzed and adequate facilities provided and planned to match the needs of the pupils (Olaitan et al, 1999).

According to Moon [16]; the design of industrial arts laboratories has too often been premised on present and past circumstances, without a critical look to the future. In an area of rapid curriculum change, such as presently being experienced in industrial education, this procedure can result in facility obsolescence before construction is completed. Educators and architects need to work together to design facilities which will be functional in fulfilling the needs of students in the future. The design of today's facilities should gear towards emerging curriculum programmes and new international approaches in industrial education [14]. But Fowler [11] and Asiabaka [1], in separate works, agreed that it is imperative that workshop facilities be designed with adequate flexibility in order for the utilities to cater for continued advancement in technology and change of taste in all aspects of human endeavour. Moon [16] schematically showed what to put in view when planning:

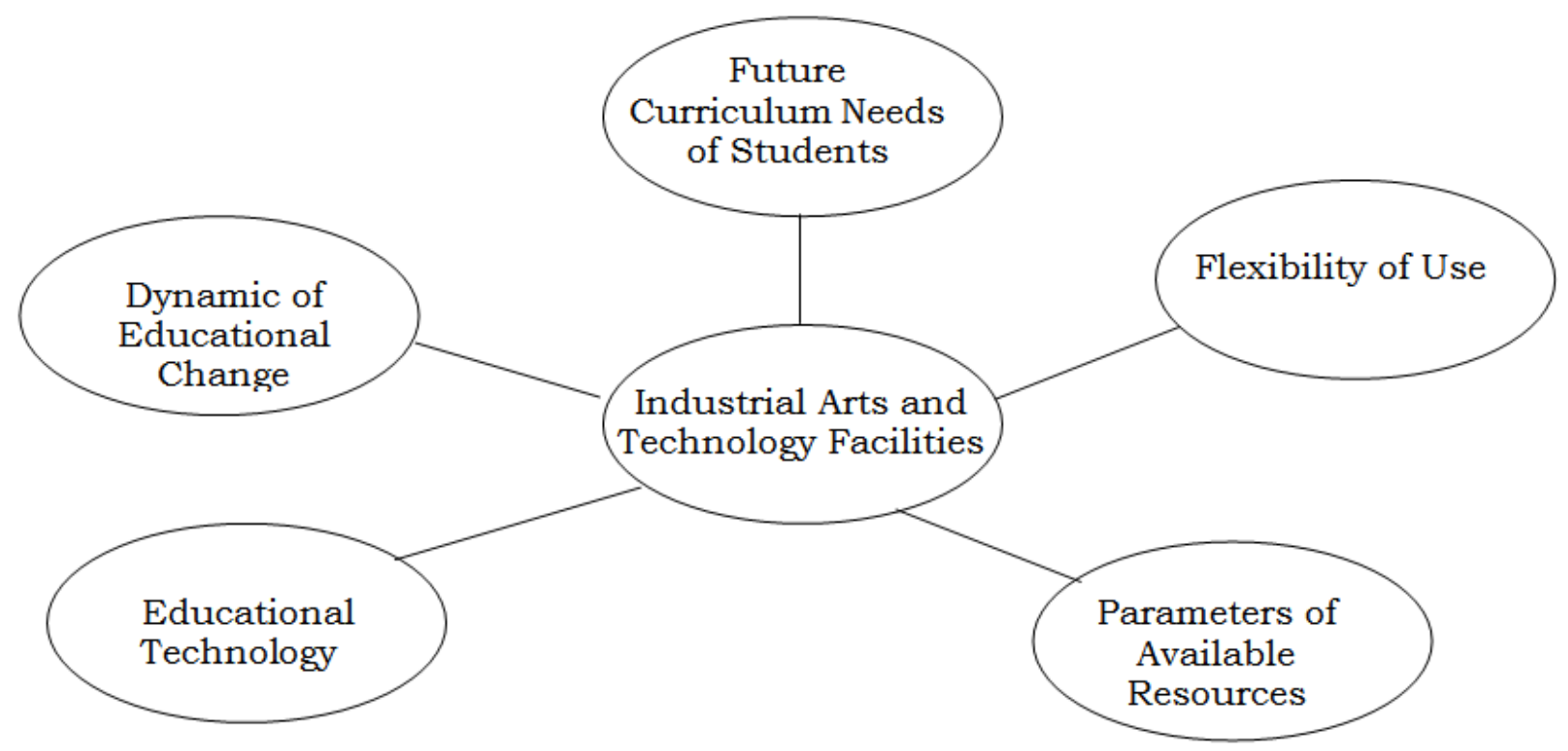

Figure 1. Factors in Facility Design (Source: Moon, [16])

Nwachukwu [17(2003) emphasized that good planned facilities give the impetus for effective learning. He went on to give some hints on effective planning of workshop facilities viz: grouping arrangement for learners to ensure effective laboratory work; allocation of materials and equipment to groups or individuals; available supportive personnel to assist learners by way of providing their specific needs and a conducive environment for workshop 
activities. Effective school facility planning would; contribute to an organizations instructional effectiveness and financial well - being; improve the cleanliness, orderliness and safety of an educational organization's facilities; reduce the operational costs and life cycle lost of a building; help staff deal with limited resources by identifying facilities priorities proactively rather than reactively; extend the useful life of buildings; increase energy efficiency and help the environment [14]. For effective realization of the objectives of basic technology under the Universal Basic Education in Nigeria, it becomes a necessity that members of workshop and nonworkshop staff imbibe the culture of strategic planning at the point of installing and eventual utilization of workshop facilities so as to enhance the pupils’ practical experience.

\section{Statement of the Problem}

In the year 2007, the Universal Basic Education scheme introduced basic technology to replace introductory technology, with a desire to achieve what could not be realized through introductory technology. Same teachers of introductory technology and other workshop staff are used to implement basic technology. Workshops used for introductory technology are still being used for basic technology. According to Toby, [25], students cannot learn skills of their chosen occupation at maximum efficiency with poor and obsolete equipment, neither will the students develop positive attitudes towards the use of tools and equipment of their trade if the laboratories/workshops are not properly managed and facilities inadequately maintained. Therefore the problem of this study, put in question, is "How will basic technology workshops be planned to improve the teaching and learning of the course in Nigeria?

\subsection{Design of the Study}

Survey research design was used for this study. Stratified and Purposive sampling techniques were used in selecting the sample for this study. These two methods were used to account for the difference in the characteristics of strata of the population for the study. Simple random sampling was used to select respondents among the administrators and the basic technology teachers. Purposive sampling technique was used in selecting respondents among the workshop staff, in order to sample only those basic technology workshop staff who posses Ordinary National Diploma (OND) and above. A total of 861 respondents were sampled from the population for the study.

This study used structured questionnaire of Likert scale response categories. The researcher administered the questionnaire to the respondents with the help of 17 research assistants. Three research assistants each distributed and retrieved the questionnaire in five geopolitical zones, while the researcher and two assistants were responsible for the south-east zone. Mean statistic and standard deviation were used to answer the research question. Any item with a mean of 3.50 and above was considered as a technique needed for basic technology workshop planning. Any item below the mean of 3.50 was regarded as not needed. The hypothesis was analyzed using Analysis of Variance, (ANOVA).

\section{Presentation and Analysis of Data}

\subsection{Research Question}

What are the workshop planning techniques needed to improve the teaching and learning of basic technology in Nigeria?

Table 1. Mean Responses of the Respondents on the Workshop Planning Techniques Needed to Improve the Teaching and Learning of Basic

\begin{tabular}{|c|c|c|c|c|}
\hline $\mathrm{S} / \mathbf{N}$ & Item Statements & $\dot{\mathbf{x}}$ & SD & Remarks \\
\hline 1 & Ensuring the availability of equipment to be used for instruction & 4.14 & 1.00 & Needed \\
\hline 2 & Ensuring the availability of tools to be used for instruction & 3.91 & 0.81 & Needed \\
\hline 3 & Ensuring the availability of materials to be used for instruction & 3.92 & 1.05 & Needed \\
\hline 4 & Identification of practical lesson objectives & 3.99 & 0.97 & Needed \\
\hline 5 & Consideration of duration for the workshop lesson & 3.84 & 0.71 & Needed \\
\hline 6 & Grouping of the lessons based on available work stations & 3.86 & 1.00 & Needed \\
\hline 7 & The instructional media have to be designated & 3.69 & 0.84 & Needed \\
\hline 8 & Listing clearly the roles expected to be performed by the teacher & 4.06 & 0.87 & Needed \\
\hline 9 & Clearly stating the roles to be performed by the students & 4.18 & 0.82 & Needed \\
\hline 10 & Deliberate decisions should be taken on the suitable time for workshop lessons & 4.12 & 0.87 & Needed \\
\hline 11 & Drawing up step-by-step procedure to be used in carrying out each task. & 4.18 & 0.88 & Needed \\
\hline 12 & Preparation of learning sequence to be adopted & 4.20 & 0.94 & Needed \\
\hline 13 & Listing in order, the learning activities to be done & 3.90 & 0.98 & Needed \\
\hline 14 & Examining the tools and materials necessary for the activities to be performed & 4.15 & 0.86 & Needed \\
\hline 15 & Arrangement of workshop facilities based on current students' enrollment & 4.05 & 0.81 & Needed \\
\hline 16 & Arrange to put up workshop facilities based on projected students' enrollment & 3.75 & 0.88 & Needed \\
\hline 17 & Arrange to set up the workshop layout with adequate gangways and work areas & 3.68 & 0.93 & Needed \\
\hline 18 & Provision for suitable water within the workshop & 3.54 & 0.92 & Needed \\
\hline 19 & Provision for adequate number of staff offices in the shop & 3.43 & 0.71 & Not needed \\
\hline 20 & Provision for adequate number of toilets and bathrooms & 3.54 & 0.87 & Needed \\
\hline 21 & Provision for adequate demonstration area for workshop lesson in the shop & 3.68 & 0.85 & Needed \\
\hline 22 & Provisions for adequate ventilation and illumination in the workshop. & 3.80 & 0.86 & Needed \\
\hline 23 & Arrange to locate machines switches and socket outlets for convenience and safety. & 3.64 & 0.72 & Needed \\
\hline 24 & To locate the machines and equipment appropriately on the workshop floor. & 4.28 & 0.83 & Needed \\
\hline 25 & Provisions for students to have easy access to materials, tools and equipment & 4.11 & 0.83 & Needed \\
\hline
\end{tabular}


The data presented above revealed that 24 out of 25 workshop planning techniques had their mean values ranged from 3.54 to 4.28 . This showed that the mean value of each item was above the cut-off point of 3.50 , indicating that only 24 out of 25 workshop planning techniques are needed to improve the teaching and learning of basic technology in Nigeria. The table also showed that the standard deviations (SD) of the items are within the range of 0.71 to 1.05 ; this indicated that the opinions of the respondents were not far from one another in their responses.

\subsection{Hypothesis}

There is no significant difference in the mean responses of the school administrators, basic technology teachers and the workshop staff on the planning techniques needed to improve the teaching and learning of basic technology in Nigeria.

Table 2. Analysis of Variance (ANOVA) of the Mean Ratings of Respondents on the Planning Techniques needed to improve the Teaching and Learning of Basic Technology in Nigeria

\begin{tabular}{ccccccc}
\hline Sources of Variance & Sum of Squares & Df & Mean Square & F-cal & F-tab & Remarks \\
\hline Between Groups & 4.631 & 2 & 2.315 & 1.148 & 3.00 & NS \\
Within Groups & 417.483 & 207 & 2.017 & & & \\
Total & 422.114 & 209 & & & &
\end{tabular}

This result indicated that calculated F-value (1.148) was less than the Table $F$ ratio of 3.00 at 0.05 level of significance and degree of freedom 2 and 207. This indicated that there was no significant difference in the mean responses of the school administrators, basic technology teachers and the workshop staff on the planning techniques needed to improve the teaching and learning of basic technology in Nigeria. Therefore, the null hypothesis was upheld

\subsection{Findings from the Study}

The following findings emerged from the study regarding what is needed to improve the teaching and learning of basic technology in Nigeria:

1. Ensuring the availability of equipment to be used for instruction

2. Ensuring the availability of tools to be used for instruction

3. Ensuring the availability of materials to be used for instruction

4. Identification of practical lesson objectives

5. Consideration of duration for the workshop lesson

6. Grouping of the lessons based on available work stations

7. The instructional media have to be designated

8. Listing clearly the roles expected to be performed by the teacher

9. Clearly stating the roles to be performed by the students

10. Deliberate decisions should be taken on the suitable time for workshop lessons

11. Drawing up step-by-step procedure to be used in carrying out each task.

12. Preparation of learning sequence to be adopted

13. Listing in order, the learning activities to be done

14. Examining the tools and materials necessary for the activities to be performed

15. Arrangement of workshop facilities based on current students' enrollment

16. Arrange to put up workshop facilities based on projected students' enrollment

17. Arrange to set up the workshop layout with adequate gangways and work areas

18. Provision for suitable water within the workshop

19. Provision for adequate number of toilets and bathrooms
20. Provision for adequate demonstration area for workshop lesson in the shop.

21. Provisions for adequate ventilation and illumination in the workshop.

22. Arrange to locate machines switches and socket outlets for convenience and safety.

24. To locate the machines and equipment appropriately on the workshop floor.

25. Provisions for students to have easy access to materials, tools and equipment.

\section{Discussion of Findings}

The findings of this study revealed that the respondents agreed that 24 workshop planning techniques are needed to improve the teaching and learning of basic technology in Nigeria. These workshop techniques include ensuring the availability of materials to be used for instruction, identification of practical lesson objectives, consideration of duration for the workshop lesson and grouping of the lessons based on available work stations. These findings were in agreement with Olaitan, et al (1999); Okoro, [21] and Nwachukwu, [18] that workshop planning skills were required by the teachers of pre-vocational courses in the Junior Secondary Schools in Nigeria for effectiveness in their workshop practices.

\section{Recommendations}

Based on the findings of the study, the following recommendations were made:

1. Administrators should try to organize workshop and seminars for teachers and other staff of basic technology on effective workshop planning techniques to improve the teaching and learning of basic technology in secondary schools across the nation.

2. Relevant technology bodies or employers of the products of technology should be encouraged by government to also organize and or sponsor seminars for teachers and other staff on best ways to plan workshops in order to achieve objectives of basic technology.

3. Only qualified teachers and other basic technology staff who have skills in proper workshop planning 
techniques should be recruited to teach basic technology in secondary schools across the country.

4. Federal, state and local governments in Nigeria should provide more workshops, planned in line with the objectives of basic technology for all the Junior Secondary Schools within their jurisdiction.

5. Institutions of higher learning which run technology and technology related programmes should include workshop planning techniques as a core course of study to be passed for any of their student to graduate.

6. The Universal Basic Education Commission should ensure that every basic technology workshop in Nigeria is planned in line with the stated objectives of the course.

\section{References}

[1] Asiabaka, I. P. (2008). The Need for Effective Facility Management in Schools in Nigeria. New York: Science Journal 1(2): 10-21.

[2] Babu, A. R.; Singh V. P. and Sachdeva, R. K. (1997). Establishing a Management Information Systems. In B.E. Swanson et al (Eds). Improving Agricultural Extension, (108 - 134). A Reference Manual Rome: FAO.

[3] Comparative Education Study and Adaptation Center (2007). Introductory Technology for Junior Secondary Schools: Ikeja, Lagos: Longman.

[4] Dror, Y. (1967). The Planning Process: A Facet Design in Planning, Programming and Budgeting. In F.G. Lyden and E.G. Mitter (eds). A System Approach to Management (pp.91-101). Chicago: Markham Publishing Company.

[5] Esomonu, N. P. M. (2002). Analysis of Inadequate Infrastructure in Technology Education: Focus on Workshop/Laboratory Practice. Journal of Technical Education, Research and Development 1 (1): 24-31.

[6] Ezeji S. C. O. A. (2004). A Guide to Preparing Educational Specifications for Secondary Industrial Arts Facilities. Enugu: Cheston Agency.

[7] Fakomogbon, M. A. (2004). The Laboratory in Introductory Technology: Some Basic Considerations and Needs. Nigerian Journal of Education 3(1): 38-46

[8] Federal Ministry of Education (2007). 9- Year Basic Education Curriculum; Basic Technology for JS 1-3. Abuja: Nigeria Education Research and Development Council.

[9] Federal Government of Nigeria (2009). Basic Technology for Schools. Lagos: Comparative Education Study and Adaptation Centre.

[10] Fenker, O. M. (2004). Organizational Change, Representations and Facilities. In K. Alexander (Ed). Facilities Management; Innovation and Performance. U.K: Taylor Francis.
[11] Fowler, R. J. (1975). Technology, Status and Trends. In D.E. Moon, (Ed); A Guide to the Planning of Industrial Arts Facilities. $24^{\text {th }}$ year Book, pp. 21-32. Illinois: American Council of Industrial Arts Teacher Education.

[12] Glagola, J. R. (2002). An Introduction to Strategic Facilities Planning. Real Estate Issues. 27(1): 13-15.

[13] Grimaldi, J. V. and Simonds, R. H. (1975). Safety Management ( $3^{\text {rd }}$ Edition). Illinois: Richard D. Irwin Inc.

[14] IFMA (2009). A White Paper on Strategic Facility Planning. Retrieved on May, 18, 2010 from http://www.ifma.org.

[15] Mohammed, I.D. (2006). Workshop Facilities Management Techniques Adopted by Technical Staff in Institutions Offering Technical Teacher Education in North Western Nigeria. Unpublished M.Ed Thesis. UNN: Department of VTE.

[16] Moon, D. E. (1975). Introduction. In D. E. Moon (Ed). A Guide to the Planning of Industrial Arts Facilities (24 ${ }^{\text {th }}$ Year Book) (pp. 1520). Illinois: American Council on Industrial Arts Teacher Education.

[17] Nwachukwu, C. E. (2003). Strategic Influence of UBE on the Education of Migrant Farmers in Imo State. The Nigerian UBE Journal 1(2): 141-145.

[18] Nwachukwu, C. E. (2006). Designing Appropriate Methodology in Vocational and Technical Education for Nigeria. Nsukka: University Trust Publishers.

[19] Ogwo, B. A. (2003). Management of Industrial Education Laboratory. Unpublished manuscript. U.N.N: Department of VTE.

[20] Ogwo, B. A. and Oranu, R. N. (2006). Methodology in Formal and Non - Formal Technical/Vocational Education. Nsukka: University of Nigeria Press.

[21] Okoro, O. M. (2006). Principles and Methods in Vocational and Technical Education. Nsukka: University Trust Publishers.

[22] Oranu, R. N. (2004). Strategies for Teachers Coping with the New Curriculum. Retrieved on April 15, 2010 from http://www.ibe.unisco.org/regional/africanproject/africapdf/lagon igeri.pdf.

[23] Steiss, A. W. (2004). Strategic Facilities Planning: Capital Budgeting and Debt Administration. London: Lexington Books.

[24] Tahir G. (2004) Nigeria: An Overview of the Nigerian Education Policy and a Justification for UBE. Retrieved on April 15, 2010 from

http://www.ibe.unesco.org/regional/africanproject/africapdf/lagon igeri.pdf.

[25] T. U. (2000). Essentials of Management and Leadership in Vocational and Technical Education ( $2^{\text {nd }}$ Edition). Jos: Nigerian Association of Technology Teachers.

[26] UBEC (2008). Universal Basic Education Commission Training Manual on the New 9 Year Basic Curriculum, Abuja: Britek Printing Press

[27] UNESCO (2001). Instruments Concerning the Institutional Framework for Training: Revised Recommendations Concerning Technical and Vocational Education. Retrieved on June 18, 2010 from http://www.lagos-net.net/ilo/150base/en/tropic-i/tizuries.htm. 